\section{Benefits and Challenges of Instructing Introductory Biology Course-Based Undergraduate Research Experiences (CUREs) as Perceived by Graduate Teaching Assistants}

\author{
Ashley B. Heim* and Emily A. Holt \\ School of Biological Sciences, University of Northern Colorado, Greeley, CO 80639
}

\begin{abstract}
Graduate teaching assistants (GTAs) are often the primary instructors for undergraduate biology laboratories and serve as research mentors in course-based undergraduate research experiences (CUREs). While several studies have explored undergraduate perceptions of CUREs, no previous study has qualitatively described GTAs' perceptions about teaching CUREs, despite the essential instructional role GTAs play. The purpose of this phenomenological study was to describe and ascribe meaning to the perceptions that GTAs have regarding benefits and challenges with instructional experiences in introductory biology CUREs. We conducted semistructured interviews with 11 GTAs instructing an introductory biology CURE at a 4-year public university. We found that, while GTAs perceived professional benefits such as experience in research mentoring and postsecondary teaching, they also described challenges, including the time required to instruct a CURE, motivating students to take ownership, and a lack of expertise in mentoring undergraduates about a copepod-based CURE. Feelings of inadequacy in serving as a research mentor and high levels of critical thinking were also cited as perceived issues. We recommend that the greater responsibility and increased time commitment perceived by GTAs in the current study warrants reconsideration by lab coordinators and administrators as to what content and practices should be included in pedagogical training specifically designed for CURE GTAs and how departmental and institutional policies may need to be adapted to better implement CUREs.
\end{abstract}

\section{INTRODUCTION}

Course-based undergraduate research experiences (CUREs) offer authentic research laboratory experiences to all undergraduates rather than a select few who are able to acquire highly sought-after internships or apprenticeships (Harrison et al., 2011; Wei and Woodin, 2011). Generally, CUREs allow individuals or groups of students within a laboratory to ask unique research questions, and often these questions are novel and relevant to the scientific community at large. Auchincloss et al. (2014) suggest that, to be defined as a CURE, science laboratory experiences must 1) use scientific practices, 2) involve discovery, 3) include relevant research questions, 4) promote collaboration, and 5) iterate parts of the research process. Importantly, in contrast to many other science laboratories that still rely on "cookbook labs" for student learning, the novel research projects conducted during CUREs often have outcomes unknown to the laboratory instructors and the students when they begin (Domin, 1999; Buck et al., 2008; Weaver et al., 2008; Dolan, 2016).

Multiple studies have reported the benefits of undergraduate participation in CUREs, including improvements in their research skills, persistence in science, technology, engineering, and mathematics (STEM) fields, and self-regulated learning
Stephanie Gardner, Monitoring Editor Submitted Sep 17, 2018; Revised May 17, 2019: Accepted Jun 17, 2019

CBE Life Sci Educ September 1, 2019 18:ar43 DOI:10.1187/cbe.18-09-0193

*Address correspondence to: Ashley B. Heim (ashley.heim aunco.edu).

(c) 2019 A. B. Heim and E. A. Holt. CBE-Life

Sciences Education @ 2019 The American Society for Cell Biology. This article is distributed by The American Society for Cell Biology under license from the author(s). It is available to the public under an Attribution-Noncommercial-Share Alike 3.0 Unported Creative Commons License (http://creativecommons.org/licenses/ by-nc-sa/3.0)

"ASCB®" and "The American Society for Cell Biology $\AA^{\circledR}$ are registered trademarks of The American Society for Cell Biology. 
(Lopatto et al., 2008; Shaffer et al., 2010; Harrison et al., 2011; Rowland et al., 2012; Auchincloss et al., 2014; Jordan et al., 2014; Corwin et al., 2015; Rodenbusch et al., 2016; Hanauer et al., 2018). Increases in students' content knowledge and project ownership have also been measured after participation in a CURE (Corwin et al., 2015, 2018; Hanauer et al., 2018). Students involved in a CURE course were generally more successful in finding undergraduate research opportunities, including competitive internships (Shaffer et al., 2010; Rowland et al., 2012; Jordan et al., 2014).

Laboratory instructors at many larger institutions tend to be graduate teaching assistants (GTAs) rather than members of the faculty; in fact, GTAs may constitute up to $50 \%$ of all instructors at research universities (Baldwin and Wawrzynski, 2011). GTAs frequently instruct introductory laboratories that are prerequisites for upper-division courses; therefore, GTAs can play a significant role in undergraduate student skill building and, ultimately, student retention (Benjamin, 2002; Jaeger, 2008). Unfortunately, Goodwin et al. (2018) report that biology graduate students are willing to implement teaching practices supported by literature (e.g., case studies, student response devices, in-class discussions; Handelsman et al., 2004; Tanner, 2013), yet feel they lack sufficient professional development to do so effectively. The Biology Teaching Assistant Project (i.e., BioTAP) was developed in 2013 primarily to assemble teaching professional development resources for graduate students and encourage research on graduate students instructing biology labs (BioTAP, 2019). While BioTAP is a first step in improving graduate student pedagogical development in biology, graduate students teaching biology labs but not familiar with biology education research may not be aware of this resource, thus exacerbating the issue of insufficient professional development.

This need for more research on GTAs as the primary instructors of CUREs extends not only to pedagogical training that graduate students will use during their programs, but for skills they will need afterward. Doctoral programs in the sciences often focus on core competencies related to the ability to conduct scientific research rather than on teaching skills (National Academies of Sciences, Engineering, and Medicine, 2019; National Institutes of Health, 2019). However, the greatest proportion of U.S. doctoral recipients in the life sciences find employment in academia (45.5\%; National Science Foundation, 2016), where teaching is part of their job duties. Further supporting these short- and long-term needs, and to ease tension associated with teaching and research requirements among graduate students in the life sciences, increased investment by graduate students in evidence-based teaching was not found to interfere with their research progress, based on large-scale survey results (Shortlidge and Eddy, 2018).

Research on CUREs has largely neglected the impact on laboratory instructors-GTAs; instead, undergraduate students tend to be the focal population for this research (Howard and Miskowski, 2005; Gormally et al., 2009; Brownell et al., 2012). While some have researched the belief systems of science faculty teaching inquiry-based courses (Crawford, 2007; Hutchins and Friedrichsen, 2012), to our knowledge there is no research available founded on GTA perceptions regarding the implementation of CUREs in the introductory biology laboratory, particularly using qualitative methods.
Regarding the limited literature available on GTAs instructing CUREs, Volkmann and Zgagacz (2004) conducted a qualitative study on a single GTA's experiences teaching a non-CURE inquiry-based course for pre-service elementary school teachers. Additionally, Shortlidge et al. (2016, 2017) conducted qualitative interviews with faculty members teaching life sciences CUREs to better understand faculty perspectives of CURE instruction and improve implementation of CUREs at the institutional level. Compared with quantitative research, which sometimes reduces an individual to a single value or data point, qualitative studies provide more vivid descriptions of an individual's or group's experience (Taylor et al., 2015). Our study, unlike that of Volkmann and Zgagacz (2004), focused specifically on the experiences of multiple GTAs instructing an introductory biology CURE at a 4-year public university, thus providing insight into the shared experiences of GTAs teaching the same course.

The purpose of our phenomenological study was to describe and ascribe meaning to the perceptions that GTAs have regarding benefits and challenges with instructional experiences in introductory biology CUREs. We hoped to gain from this study a better understanding of the meaning of experiences that GTAs have while instructing introductory biology CUREs. This research could inform structuring of both laboratory CURE courses at postsecondary institutions and professional development for GTAs instructing introductory biology CUREs.

\section{METHODS}

We sought to construct meaning from GTA perceptions of teaching introductory CUREs, based on Crotty's (1998) suggestions. Therefore, the epistemological perspective guiding us in this study was constructivism.

\section{Researcher Stance}

A.H. was formerly a GTA for an introductory biology laboratory that had been redesigned as a CURE at the university where the research was conducted, and both researchers felt that additional pedagogical training may be needed for GTAs instructing this course based on anecdotal feedback from graduate students in the department. Both researchers have also been involved in preparing undergraduate teaching assistants to develop recitation materials and assist with laboratory exercises in this same CURE. Subsequently, both researchers became interested in how GTAs perceive instructional experiences in CUREs. On the basis of our epistemological stance, we chose a phenomenological study. The principal objective of phenomenological studies is to "illuminate the specific, to identify phenomena through how they are perceived by the actors in a situation" (Lester, 1999, p. 1). Often, this research occurs through interviews and discussions and is generally based on the assumption that "there is an essence or essences to shared experience" (Merriam and Tisdell, 2016, p. 26). Our goal of better understanding the essence of an instructional experience in a biology CURE paralleled our epistemological view and the constructionist theory of learning, as we sought to construct meaning from GTA perceptions of a common experience (i.e., instructing CUREs).

\section{Participants and Course Description}

The institutional review board of the comprehensive university in the western U.S. where this research was conducted approved 
the procedures for this study (IRB \#1140836-2). This university had an enrollment of almost 2500 graduate students and 9000 undergraduates. GTAs instructing an introductory biology laboratory CURE were solicited for participation via convenience sampling (Creswell, 2013) in Fall 2017 via recruitment letters emailed to potential participants. Eleven of 14 possible GTAs in Fall 2017 made up our sample. In total, seven female and four male GTAs participated in interviews; all GTAs were enrolled in either MS ( $n=4$ thesis; $2=$ nonthesis) or $\mathrm{PhD}$ programs $(n=5)$ in the biological sciences. Our participating GTAs had differing undergraduate teaching experiences (less than 1 year of teaching experience: $n=6 ; 1$ year of experience: $n=3 ; 2$ years of experience: $n=1 ; 3$ years of experience: $n=1$ ), which likely influenced their individual responses. For GTAs who had less than 1 year of teaching experience, instructing the CURE was their first teaching experience at the postsecondary level. For the purposes of this manuscript, we classified GTAs who had 1 year of teaching experience or less as novice teachers $(n=9)$, while GTAs who had more than 1 year of teaching experience were identified as experienced or expert teachers $(n=2)$. Both expert GTAs had taught at least one semester of this introductory biology CURE in a previous semester.

The CURE laboratory met weekly for a 3-hour block to complement the introductory biology lecture that met two or three times, for a total of 150 minutes, per week. The first 6 weeks of the CURE lab were dedicated to learning basic scientific techniques (Olimpo et al., 2016) and project planning. Within lab groups of no more than four people, students were expected to develop a novel research question and proposal using Tigriopus californicus, a marine copepod, as the model organism. These research questions had not been previously studied by experts in the copepod field and were identified through students' independent research and GTA suggestions. Working with their GTAs, students formulated testable hypotheses and designed experimental procedures specific to their group research projects. After the sixth week of this CURE and through to the end of the semester, laboratory sessions were dedicated primarily to collecting, analyzing, summarizing, and presenting data. GTAs were expected to provide foundational background information regarding general research project planning and development of lab skills, often in the form of a short (i.e., 10 minutes or fewer) slideshow presentation or hands-on demonstration at the start of lab. GTAs also gathered necessary experimental materials for students, offered resources when students had project-specific questions, and assisted students in staying on task and organizing within their research groups. GTAs served as a resource for students in this CURE experience, while students independently ran their research projects with limited intervention from the GTA.

At this institution, GTAs can request to teach this introductory biology CURE, although most lab instructor positions for this course are filled based on availability of GTAs rather than preference, as there are often upward of 30 lab sections; thus, GTA turnover from semester to semester is unpredictable. However, we did not have access to each GTA's teaching preferences in Fall 2017, so we cannot comment on whether GTAs requested to teach this course or were chosen at random by faculty members. GTAs did not receive pedagogical training focused specifically on teaching the CURE, although they did meet weekly with the faculty lab coordinator to discuss lab content, logistics, and issues related to the CURE. Every GTA at this institution must attend a mandatory daylong teaching conference each year, and all first-year GTAs take a pedagogical course concurrently to explore instructional strategies related to laboratory teaching.

\section{Methods for Data Collection}

We used semistructured, one-on-one interviews in Fall 2017 as the research instrument (Merriam and Tisdell, 2016). Interviews took place 8 to 14 weeks into a 16-week semester, with each participant being interviewed once. Interviews were scheduled near the end of the semester to allow for GTAs to fully experience all aspects of CURE instruction (rather than just the chaotic first few weeks when projects are being developed and materials for each group are organized) and to allow first-time GTAs to fully acclimate to the teaching requirements of the department. Each interview lasted approximately 30-60 minutes and took place in a private research space on campus. As only the researchers had access to this room, it was an effective setting to conduct private interviews with and collect sensitive information from the participants. Participants were asked to sign a consent form before the interviews. Each interview consisted of seven questions (Table 1), and each session was audio-recorded. Although Table 1 includes the entire

\section{TABLE 1. GTA interview questions ${ }^{a}$}

1. What do you believe are the benefits of an introductory biology CURE for undergraduate students?

2. What do you believe are the benefits of an introductory biology CURE for GTAs?

3. What do you believe are the challenges of an introductory biology CURE for undergraduate students?

4. What do you believe are the challenges of an introductory biology CURE for GTAs?

5. Is your role as a mentor in the CURE more challenging than your role as a GTA in other laboratory courses you have taught? Explain your response.

6. What changes would you make to the CURE to make it a more effective learning experience for undergraduate students?

7. Have you had experiences with CUREs previously, in high school or college? Reflect on your previous high school and college laboratory experiences.

If answer YES to previous experience with CUREs:

a. Do you feel that you have benefited from participating in CUREs in previous lab courses? Explain.

b. Do you feel that participating in CUREs in previous lab courses was challenging? Explain.

If answer NO to previous experience with CUREs:

a. Do you feel that you have benefited from not participating in CUREs in previous lab courses? Explain.

b. Do you feel that not participating in CUREs in previous lab courses was challenging? Explain.

${ }^{a}$ Although all of the interview questions were asked of participants, questions 2,4 , and 5 were primarily used for thematic analysis in our study. 
interview protocol, we should note that we analyzed and reported on only a subset of these questions (i.e., questions 2 , $4,5,6$, and 7) that were most related to the GTA teaching experience rather than the undergraduate learning experience. After interviews, participants were asked to complete a demographic questionnaire. We use pseudonyms in place of participant names throughout the article.

\section{Data Analysis}

We used a thematic analysis approach to analyze qualitative interview data. Interviews were transcribed from audio recordings and inductively coded into naturally emerging themes (Bogdan and Taylor, 1989; Aronson, 1994) using NVivo 12 software (QSR International, 2018). Identified themes were then amalgamated into a rich description of the phenomenon. Data saturation seemed to occur by the ninth interview, although to ensure that perceptions between novice versus expert and male versus female GTAs were fully accounted for, we completed all 11 interviews that we had originally scheduled.

A.H. completed an initial coding of all raw interview data through development of a preliminary codebook. E.H. conducted a coding consistency check (Thomas, 2006) by using the same codebook to assign all text to the initial themes. We then reviewed any disagreements in coding together and came to a final consensus on a final codebook and the coding of all references. Intercoder agreement increased the reliability of our interpretations, despite only having two researchers involved in the data analysis process (Creswell, 2013). Similar to Creswell's (2013) description, this form of peer checking involved coding the interview transcripts and later meeting in person to discuss and justify emergent themes, names, and text segments. See Table 2 for a summary of challenges and benefits derived from thematic analysis, including a tally of how many total GTAs and how many GTAs from each category of teaching experience cited each theme during their interviews.

\section{Relevance to Existing Theories}

After inductively coding the GTA interviews, we based our postthematic analysis on two primary theories: 1) Tinto's (1993) theory that successful socialization and professional development often leads to the persistence of graduate students in their degree programs; and 2) adult learning theory (Knowles, 1975), which incorporates self-directed learning and recognizes that faculty experience various issues during faculty development such as time limitations and varying levels of motivation to improve. Further, adult learning theory as it applies to faculty development also takes into account how prior teaching and learning experiences of faculty may influence their instructional practices and willingness to reform these practices. In the context of GTA perceptions of teaching, we propose that both theories provide insight into why GTAs may have described the CURE-specific benefits and challenges that they did in the current study; further, perhaps the citing of many more challenges than benefits by GTAs suggests that awareness and incorporation of these theories in current GTA professional development programs is limited.

\section{FINDINGS AND DISCUSSION}

Overall, GTAs identified seven primary challenges and two primary benefits to teaching an introductory biology CURE (Table 2). Though these responses reflect the perceptions shared by GTAs at our specific institution, we believe the following challenges and benefits could be characteristic of the experiences of GTAs teaching CUREs at other institutions as well; however, additional interviews at other institutions would need to be conducted to confirm this speculation. Challenges are ordered from most to least commonly mentioned by the GTAs, although similar patterns in thematic prevalence emerged when using the total number of statements cited per theme rather than by individual GTAs. The two benefits are also ordered in this same manner.

\section{What Challenges Do GTAs Perceive for Themselves in Teaching CUREs? Academic Unreadiness of First-Year Undergraduates}

Findings. Eight GTAs referred to the composition of their student population (i.e., primarily first-year introductory biology students) as an instructional challenge (Table 2). Jennifer noted,

The [CURE] students tend to be freshmen who are coming out of high school where they're not given a very realistic picture of what the college experience is like ... so that's a huge challenge because they're just getting used to college to begin with and then they have to carry out their own research project. It's a bit overwhelming [for them].

Katelyn similarly explained,

TABLE 2. Challenges and benefits for GTAs instructing CUREs based on thematic analysis ${ }^{a}$

\begin{tabular}{|c|c|c|c|c|}
\hline & \multirow[b]{2}{*}{ Themes } & \multirow[b]{2}{*}{ Total GTAs $(n=11)$} & \multicolumn{2}{|c|}{ Teaching experience } \\
\hline & & & Novices $(n=9)$ & Experts $(n=2)$ \\
\hline \multirow[t]{7}{*}{ Challenges } & 1. Academic unreadiness of first-year undergraduates & 8 & 7 & 1 \\
\hline & 2. Feelings of inadequacy in serving in a supervisory capacity & 6 & 6 & 0 \\
\hline & 3. Logistics & 6 & 5 & 1 \\
\hline & 4. Motivating students to take ownership of their work & 5 & 3 & 2 \\
\hline & 5. Time commitment & 4 & 3 & 1 \\
\hline & 6. Lack of expertise & 3 & 3 & 0 \\
\hline & 7. CURE instruction requires lots of critical thinking by GTA & 3 & 2 & 1 \\
\hline \multirow[t]{2}{*}{ Benefits } & 1. Experience serving as a research mentor & 7 & 6 & 1 \\
\hline & 2. Practice being dynamic & 4 & 2 & 2 \\
\hline
\end{tabular}

avalues represent the total number of GTAs and the number of GTAs in each category of teaching experience who cited each challenge and/or benefit in their interviews. 
I think in their first semester, especially in biology, they're trying to fill in the gaps that they didn't learn in high school ... So they're trying to catch up while learning new information, while trying to apply that information, and while learning how to manage their time.

Camille remarked that one of the biggest challenges in dealing with predominantly freshman students is that "[the CURE] is the first time [that most students] will conduct their own experiments."

Discussion and Interpretations. This challenge is presumably an issue that all institutions offering first-year undergraduate CUREs must deal with in some form. Though Jordan et al. (2014) admitted that several aspects of CUREs need to be refined for effective implementation to first-year undergraduates, these researchers and Reason et al. (2006) also highlighted the importance of introductory CUREs in increasing persistence within the STEM fields. Regarding students' abilities to ensure the semi-independent nature of the CURE, Gormally et al. (2009) reported that students participating in a more inquiry-based laboratory appreciated the rigor of engaging in more "real" science practices, despite the frustration and challenges associated with conducting more authentic research. Additionally, self-reported gains in critical-thinking skills by students involved in undergraduate research experiences have also been measured (Gottesman and Hoskins, 2013), though the National Academies of Sciences, Engineering, and Medicine (2017) called attention to the fact that measures of critical thinking have been solely based on self-reported measures in most CURE research. Regardless, our findings and these prior studies suggest that certain aspects of CUREs may need to be redesigned for effective implementation to first-year undergraduates.

Feelings of Inadequacy in Serving in a Supervisory Capacity Findings. Six GTAs, all whom were considered novices because they had 1 year or less of teaching experience, reported feeling inadequately trained to serve as the primary instructor (i.e., in a supervisory capacity) within their lab sections (Table 2). Holly stated, "I felt bad as a new graduate student because I haven't done [the CURE], so [I felt like I was] sort of dancing around a little bit."

Shannon expressed that she did not feel adequately prepared to run a lab: "The other hard part [of mentoring students in the CURE] was being able to pretend like I knew what I was talking about. Fake it "til you make it, that's been my motto for the entire semester."

Teddy thought that GTAs teaching the CURE received insufficient pedagogical training regarding how to mediate research groups:

So many students came to me with complaints about their group members, and that's something that they should be handling ... but also I guess I'm not equipped to tell them how to handle it. I can tell them what I've done in the past with my groups, but we weren't given any directive on what to tell students that come to us complaining about group members.

Specific to the role of the GTA as a research mentor, Ben remarked that a challenge of supervising the CURE was that "you kind of have to individually learn about each [student's] project for you to be able to effectively mentor them."

At least for this specific CURE, it seemed that the GTAs' struggle in a supervisory capacity as a mentor encompassed a limited knowledge of 1) the biological system (i.e., marine copepods), 2) the details of each group's specific research project, and 3) how to manage groups effectively.

Discussion and Interpretations. Our findings are supported by Shannon et al. (1998) and French and Russell (2002), who suggested that GTAs required to instruct inquiry-based labs often receive insufficient training and have limited professional socialization (Gardner and Barnes, 2007), as well as Tinto's (1993) theory of graduate students' professional development. First-time GTAs are often just beginning to engage in the scientific research process, while simultaneously developing their individual teaching philosophies and practices, and may not be familiar with the nuances of serving in a supervisory role for a demanding, learner-centered course like the CURE. Further, many graduate students reportedly have misconceptions related to the scientific research process (McPherson, 2001), which would undoubtedly make it more challenging to provide undergraduates accurate advice regarding their experiments. Therefore, it may be worth considering how first-year graduate students can more effectively prepare for their supervisory roles within the CURE via metacognitive strategies, including reflecting on their own supervisory capacity, their ability to learn from experiences, and how quickly they engage in professional socialization.

\section{Logistics}

Findings. The logistics of preparing for a lab in which every group has a unique research project was yet another challenge that was cited by six of the GTAs (Table 2). Elena referred to the first few weeks of the CURE, when students are developing and setting up their copepod research projects, as "really chaotic." Ben discussed how challenging it was to ensure that all research groups had the necessary materials to conduct their experiments: "Figuring out what everybody needed, I think that was probably the more difficult part ... figuring out how to make that run smoothly."

Jennifer voiced her concern about the cognitive stress that logistical demands of the CURE place on the GTA:

There are so many moving parts [in the CURE], you know. Running the open lab [i.e., sessions outside of class when students are able to work on their copepod research study in the teaching lab under the supervision of a GTA], helping each group that needs help with their experiment, figure out the logistics of it ... things like that aren't an aspect of a normal lab. So it's almost as if it's this idea that it's more taxing on the brain to switch tasks all the time [as a GTA].

Discussion and Interpretations. Kloser et al. (2011) and Benvenuto (2002) reported that the logistics of developing CUREs, in conjunction with the limited time and pedagogical training of CURE instructors, remain challenges of considerable magnitude. However, most discussions of CURE logistics have focused on issues at the departmental level; we suggest that logistics remain a limitation at the departmental level but also 
extend to GTAs actually instructing each lab, as CUREs, by definition, grant students the opportunity to develop novel research projects (often with unique materials and experimental designs) in groups or as individuals.

\section{Motivating Students to Take Ownership of Their Work}

Findings. Five GTAs referred to the challenge of motivating undergraduates to take ownership of their research projects during the CURE (Table 2). Katelyn noted, "I think motivation is one of the hardest and the trickiest things for these [CUREs]."

Caleb also expressed the difficulty he experienced in encouraging students to take responsibility for conducting their research projects:

In this CURE-based format I think you really have to work on convincing the student to care more about their project because the grade isn't necessarily a reflection of, did you do the work or not, [or] were you able to memorize these things ... And while that is sort of what you want to instill in students, understanding the concepts and not just memorizing things, you're kind of fighting to do that because the direct result isn't as tangible for them as a good grade is.

Discussion and Interpretations. While project ownership is often an assumed outcome of more self-directed research projects not associated with a course (Hanauer et al., 2012), students in some introductory CUREs may be too grade-motivated or disinterested in the content to fully engage. Learner-centered classrooms in general tend to promote more autonomy and ownership among students (Stefanou et al., 2004), and CUREs can be thought of as a suite of learner-centered practices that are centered around student responsibility and choice. Student responsibility for learning has been cited multiple times as a challenge of more autonomous learning environments, particularly the resistance and anxiety that students often experience when offered choices in the classroom (Howell, 2002; Hassel and Lourey, 2005). Further, Conley and French (2014) suggested that student ownership of learning is a principal component of college readiness. Because most students in this introductory biology CURE were in their first semester of college, a lack of responsibility for their research projects could be indicative of both overwhelming requirements of the CURE and academic immaturity, which then results in a perceived burden to their GTAs.

\section{Time Commitment}

Findings. Four GTAs described an excessive time commitment as one of the challenges of teaching this introductory biology CURE (Table 2); three of these GTAs referred specifically to the limited time they had to provide meaningful feedback to their students on assessments for the research project-which they stated dramatically increased their workload as a CURE GTA above the workload for non-CURE GTAs. Jennifer discussed the numerous roles she felt she was expected to play as a research mentor in the CURE:

Personally, I feel like running the CURE takes a lot of energy to be prepared, to lead so many aspects of the lab; like we covered scientific writing, lab protocol, homework, quizzes, and then experimental design ... right? All of that takes a lot of prep energy from the TAs I think to run it at a respectable level of competency. On top of that because it is so hard on the students I want to be there personally to support them with office hours, give them personal feedback on their scientific writing. I want to see them and meet with them, and so that takes even more time than the prep work that I put in. So it's like prep work, the actual labs, and then support afterwards, and ... [there is] a lot more time spent grading in this course. It's a bigger time commitment for the students, and it's a bigger time commitment for the TAs as well.

Discussion and Interpretations. This onerous time requirement perceived by the GTAs is supported by the literature. Hunter et al. (2007) discussed the time commitment and advanced planning required for faculty mentors involved in undergraduate research experiences. French and Russell (2002) described the increased workload that GTAs must endure in a more inquiry-based laboratory, including grading assessments that may not be related to the inquiry portion of the laboratory itself. Further, Bond-Robinson and Rodriques (2006) advised that, in chemistry laboratories, GTAs should provide meaningful feedback to student groups in a timely manner for students to effectively learn in a course. Though Shaffer et al. (2014) noted the importance of providing students regular feedback within a CURE, they did not specifically discuss the increased burden of formative feedback for GTAs instructing CUREs versus more cookbook labs. Based on anecdotal conversations with participants in this study, many believe that the time commitment for instructing the CURE goes beyond the scope of the GTA contract; hence, future studies at our institution and other institutions supporting similar CURE GTA workloads should focus on how to better align requirements of the GTA contract with those of CURE instruction, without compromising the integrity and purpose of the introductory biology CURE for undergraduates.

\section{Lack of Expertise}

Findings. Three of the GTAs, all novice GTAs (i.e., those teaching for 1 year or less), discussed their lack of expertise in copepod biology and/or scientific research advising in general as a challenge of teaching the CURE (Table 2). Interestingly, all GTAs who alluded to unfamiliarity with the model organism (i.e., the copepod) were first-semester graduate students and fairly new to scientific research at the graduate level. Katelyn reported, "I don't know anything about copepods ... I felt really limited on the information that I could give students. I found myself just feeling really bad that I didn't know the answers to what they asked."

Jennifer, a GTA pursuing a graduate degree without a research thesis component, also described her lack of experience in mentoring undergraduates in research and with the model organism itself:

I am not an expert in this field ... you know, ideally an adviser advising a research project would be an expert in the field, but GTAs, I mean so far none of us have been copepod experts. It's hard when there are some questions that as a GTA, I can't provide for them.

Shannon, a first-semester graduate student, similarly summarized the challenges of her role as a GTA in the CURE: "The majority of the time I'll come in [to lab] and I'll have a general idea of what I'm doing, but I'm no expert." 
Discussion and Interpretations. Some GTAs' inexperience in teaching, beyond being a new graduate student, could further explain this lack of confidence in the lab. New instructors, including GTAs, often proceed down a similar developmental trajectory in terms of pedagogical growth; Berliner (1988) proposed a five-stage model of instructor development to explain this gradual transition from novice to expert over time. Further, Sternberg and Horvath (1995) discussed that experts are better able to problem solve and synthesize relevant knowledge compared with novices. Many suggest that teachers' professional identities and pedagogies develop over time (Atkinson et al., 1987; Beijaard et al., 2000; Knowles, 2013), including shifting from a more teacher- to learner-centered mindset, and it seems reasonable that GTAs may experience a similar trajectory of personal development in teaching.

Concerns associated with a lack of expertise discussed by the GTAs in the current study are not unfounded. Research regarding GTA development has increased over the past few decades because of both faculty and GTA concerns that GTAs do not have the expertise necessary to teach at the postsecondary level (Druger, 1997; McComas and Cox, 1999). If limited guidance or training is available to GTAs instructing CURE-based laboratories (Kurdziel and Libarkin, 2003), GTAs may simply revert to using teaching practices reflective of their own instructional experiences when they were students (Halpern and Hakel, 2002).

\section{CURE Instruction Requires Lots of Critical Thinking by the GTA}

Findings. Three of the GTAs explicitly referred to the high level of critical thinking necessary to instruct the CURE (Table 2). Holly mentioned that the CURE forced her to "think creatively" and that she could not simply "copy things down" that the lab coordinators said at lab meetings for the CURE. Further, Elena discussed that "[the CURE] is a lot of brain power, not necessarily preparing the content ... but figuring out how to best approach each situation that comes up in their experiments."

Caleb similarly reported that instructing the CURE "requires a lot of thinking on the fly."

Discussion and Interpretations. While several studies have alluded to the critical-thinking demands CUREs place on students (Brownell et al., 2012; Gottesman and Hoskins, 2013; Clary and Wandersee, 2015), there is no documentation on how such demands may similarly tax the GTA as the primary CURE instructor. Therefore, we suggest that more research into the critical-thinking demands specific to instructors of CUREs in comparison to those of traditional labs should be conducted.

\section{What Benefits Do GTAs Perceive for Themselves in Teaching CUREs? \\ Experience Serving as a Research Mentor}

Findings. Seven of the 11 GTAs referred to taking on the research mentor role as being one of the more significant benefits of teaching the introductory biology CURE (Table 2). Jennifer summed up her perceived benefits as an instructor of the CURE by noting, "They come to us GTAs for questions or advice on what they're doing, the direction they're going, and how to conduct their research, so we do play that sort of advisory role."
Elena also described her perceived role as a research mentor in the CURE, highlighting the student-centered nature of the CURE and how she must communicate with students in her supervisory capacity:

[The students] look to you to help them figure out what to do, and a lot of the times they ask me questions and I'm like, I have no idea the best way to approach that but we'll sit down and think about it together. Sometimes I feel like they have great ideas and when we're bouncing ideas off of each other ... the things that they say, I'm like wow, I wish I had thought of that, that's really great. So it's nice to have that sort of synergistic problem solving going on. They have a lot of creativity, which is awesome.

Two GTAs whose program does not include a research thesis offered a unique perspective in serving as a research mentor within the CURE. Robert shared his interpretation of his role as a GTA in this introductory course: "Since we don't do thesis research, it's good for us to know [how to conduct research] and put us out there. Put us on the front lines, and be advocates for science education, how science should be done."

Discussion and Interpretations. French and Russell (2002) found that GTAs who teach more inquiry-based laboratories often gain valuable research skills necessary for their degree programs. While the effectiveness of inquiry-oriented GTA development in science laboratories has been previously studied (Hughes and Ellefson, 2013; Ryker and McConnell, 2014), to our knowledge we are the first to report that GTAs in CUREs perceive benefits from their roles as research mentors or advisors. Some of the GTAs' responses that we coded within this theme may also be akin to the socialization of graduate students for professional roles, a transition from graduate student to professional, as described by Gardner and Barnes (2007). Our findings may suggest that, at least for some of the GTAs, their instructional experience in the CURE aided in this socialization. One of our participants, Shannon, indirectly described this transition from a graduate student to a principal investigator, as she discussed the role of her research adviser overlapping with the expectations of the CURE GTA:

[My primary research adviser] really kind of made [my lab members] think [our personal research] through and kind of rationalize through it, and I think that kind of helped me [in my GTA experience] ... Now I can kind of ask the same critical questions ... about what's going wrong [in my students' CURE experiments] or maybe how we can relate to it.

\section{Practice Being Dynamic}

Findings. Four GTAs, both experts and novices, specifically referred to the dynamic mindset that teaching this course required them to develop (Table 2). In describing the flexibility that the CURE requires GTAs to foster, Caleb offered the following explanation:

First and foremost is the opportunity to practice ... there are definitely a lot of situations where things don't go as planned, and that's true for any lab, I think. In particular, [a CURE] where [the lab is] not necessarily structured to be repeated every time, I think there's a lot of opportunities where you 
have to kind of think on the fly and maybe adapt what you're teaching or what you're trying to do. And in the case of these research projects, I think it's as much of a learning experience for the GTA as it is for the undergraduate, because you don't really know what the outcome's supposed to be.

Regarding the need for CURE GTAs to adapt to an everchanging learning environment, Alicia also commented, "I've definitely gotten a lot better at multitasking."

Elena alluded to the role of the GTA in this CURE as the "ultimate problem solver," based on the ability of GTAs to respond to a multitude of questions and issues that arise.

Discussion and Interpretations. Several studies have reported that GTAs in the sciences often do not interpret their teaching duties as something that could contribute to their graduate research or progress in their degree program (Ethington and Pisani, 1993; Jones, 1993; Shannon et al., 1998). Further, Luft et al. (2004) described the limited opportunities that are generally available for GTAs to develop their pedagogy, despite the importance of flexibility in academic professions (Costin et al., 1971; Baroody, 2003). Additionally, although no other study has reported that GTAs perceive adaptability as a benefit of instructing the CURE that could be applied to aspects of their professional lives (e.g., teaching and research; Carnevale, 1990; Casner-Lotto and Barrington, 2006), instructor adaptability to individual student needs has been linked to teaching effectiveness at the K-12 level (Williams and Baumann, 2008; Parsons et al., 2011).

Interestingly, we reported earlier that some of the GTAs highlighted critical thinking as an instructional challenge of the CURE. However, this perceived challenge directly contrasts with the identified benefit of a dynamic mindset and socialization, both of which require critical thinking. Perhaps recognition of critical thinking as both a benefit and a challenge further supports the transitional status of the GTA from a student to a professional, as two of the GTAs who mentioned being dynamic as a challenge were more experienced instructors. Isaak and Hubert (1999) noted that many GTAs are inexperienced in the research process and are still developing their own criticalthinking skills, even as they instruct more inquiry-based labs.

\section{Do GTAs Find Teaching CUREs Is More Challenging Than Teaching Cookbook Labs?}

Findings. Overall, yes. Eight of the 11 GTAs stated that they believed instructing the CURE was more challenging than teaching a cookbook lab, due to the multiple reasons outlined earlier. In general, these GTAs felt that teaching the CURE was a greater responsibility, more time-intensive, and less predictable compared with teaching a cookbook lab. As Teddy remarked, "I do feel like rather than knowing something about the lab in particular, you have to know more about how to help them troubleshoot their experiment, and each experiment is different so you never know what that's going to entail."

Jennifer expanded upon the idea of greater GTA responsibility by noting, "I provide a lot more emotional support as a CURE GTA than I did as a [cookbook GTA] when we were just working out of the [lab manual]."

Ben summed up a principal challenge expressed by many CURE GTAs:
I feel like you have to learn individual projects, it's not just like you have this one thing that you're doing. Like anatomy, you just have to learn anatomy ... maybe share some memorizing tips. But for the CURE, I feel like you kind of have to individually learn about each person's project for you to be able to effectively mentor them.

However, three GTAs did express that cookbook labs were more challenging to instruct, for two primary reasons: 1) cookbook labs require more lecturing than CUREs, and 2) cookbook labs require the GTA to be more of an expert in the specific subject compared with CUREs. Camille explained,

Even my PowerPoint [introducing the learning objectives and necessary background information for CURE activities each week] doesn't exceed 10 minutes. It's to let [the students] know about today's lab, what we're going to do ... what is due. So I believe that [in other labs like] anatomy and physiology, it is more challenging. [The GTAs] have to memorize every muscle, every neuron."

Further, Shannon alluded to the content expertise necessary to teach a cookbook lab:

In my anatomy lab, it's like I'm going to spew this information at [my students] and expect [them] to remember it. That's fine and dandy but I also think that's kind of harder because then I actually have to know everything, which I do not.

In differentiating between the format of the CURE and cookbook lab, Katelyn also discussed that "CURE labs offer a lot of opportunities to talk about what went wrong, whereas cookbook labs, usually what went wrong is a part of the protocol that went wrong."

Discussion and Interpretations. When asked directly which type of lab is more challenging to teach, our GTA participants resoundingly named the CURE over a cookbook-type lab. Moreover, these same GTAs disproportionally listed far more challenges to teaching in a CURE than perceived benefits. Similarly, as many researchers have recognized that cookbook labs tend to require limited critical thinking and engagement by undergraduates (Holt et al., 1969; Modell and Michael, 1993; Brownell et al., 2012), it is not surprising that GTA responsibilities in these courses would also be less demanding (French and Russell, 2002). Considering the role of GTAs as the primary instructors of CUREs, it is worth noting these perceived challenges in the midst of nationwide reform in biology laboratory curricula toward this type of model (Brownell and Kloser, 2015). Our findings do not suggest that CUREs are inferior to traditional cookbook labs, but rather that CUREs are generally challenging for GTAs, who serve a critical role in their success. These challenges are undoubtedly further exacerbated by the "ambiguous niche" of GTAs (Park, 2004, p. 355), who are simultaneously students, teachers, and employees (Vaughn, 1998).

GTAs begin as novice instructors and budding scientists on a developmental trajectory, and their role as teaching assistants contributes to their professional growth. GTA perceptions in the current study suggest that more resources need to be allocated and more policies enacted to better support GTAs for their roles 
as CURE mentors, which are often drastically different from their roles as cookbook lab instructors (e.g., Atkinson et al., 1987; Berliner, 1988; Sternberg and Horvath, 1995; Beijaard et al., 2000; Muzaka, 2009; Knowles, 2013). Our findings hint that, with proper support, the challenges facing GTAs teaching a CURE may foster more competent and confident graduate students who have experience as leaders and critical thinkers. In sum, challenges voiced by our participants may ultimately be benefits, in that they further the complex developmental process of a GTA (e.g., metacognitive introspection of the process of science and their role therein; Barrus, 1974; Clark and McLean, 1979; Nyquist and Wulff, 1996; Druger, 1997; McComas and Cox, 1999).

\section{CONCLUSIONS, IMPLICATIONS, AND BROADER IMPACTS}

In answering our original research question "How do GTAs describe their perceptions regarding the benefits and challenges of instructing an introductory biology CURE?," we found that GTAs perceive both benefits and challenges to teaching in a CURE. While GTAs perceived professional benefits such as experience in research mentoring and postsecondary teaching, they also described certain challenges that could be addressed with better pedagogical training. This pedagogical training, which Shortlidge and Eddy (2018) suggest does not interfere with graduate students' research training and progress, could guide GTAs on how to better motivate their students to take ownership of their research projects and on best practices in mentoring undergraduates in CUREs and other lab courses in general. This is particularly important in light of Corwin et al.'s (2018) findings that the effects of discovery, iteration, and collaboration (i.e., three design features characteristic of CUREs) on the research-based career intentions of undergraduates are mediated by student ownership. Both redesigning CUREs to be more engaging and providing GTAs with the proper tools to teach and mentor effectively have the potential to positively impact the many undergraduate students enrolled in these introductory biology courses each semester, with benefits that include increasing persistence and graduation rates among STEM students (Rodenbusch et al., 2016). Additionally, at the department level, encouraging both GTA and faculty buy-in to CURE instruction could increase the likelihood of undergraduates and their CURE mentors publishing their novel project findings (Corwin et al., 2015). If GTAs teaching CUREs are truly serving the dual capacity of a mentor (i.e., providing career-related as well as psychosocial support; Kram, 1988), pedagogical training programs for CURE GTAs should focus on both practical teaching methods (e.g., designing effective assessments and grading rubrics) and more effective strategies for communicating with students in a research setting (e.g., how to be empathetic or deal with group dynamic issues).

Feelings of inadequacy in serving as a research mentor in the CURE, lack of expertise in the field, and the critical thinking required to instruct the CURE were also cited as perceived challenges, though these issues would most likely resolve themselves over time without focused pedagogical training as GTAs developed more fully in their education or within their fieldsparticularly if they have a required teaching component within their graduate degree program. GTAs further discussed the time commitment required to instruct a CURE as a notable chal- lenge; the literature, however, suggests that lack of time for instructors in higher education is a universal problem that cannot easily be remedied (Sorcinelli, 1994; Muzaka, 2009; Brownell and Tanner, 2012). Similarly, logistics may be an unavoidable challenge for GTAs in CUREs that allow students to develop and design unique research projects, although improvements in lab preparatory organization or policies to clarify GTA job duties may mitigate issues in courses with CURE labs.

Because GTAs are the primary instructors for undergraduate biology laboratories and the supervisors in CUREs, perceptions and feedback from GTAs who teach CUREs are important to consider. Our findings could inform faculty and laboratory coordinators at postsecondary institutions about which skills to focus on in professional development for GTAs instructing introductory biology CUREs, what policy changes are needed in GTA contracts, or how to more effectively implement the CURE. For example, providing GTAs with pedagogical tools at the start of the semester for responding to students' questions effectively or how to stimulate project ownership could perhaps train GTAs instructing science CUREs to be more successful research mentors. While an instrument does exist for quantifying selfreported project ownership specific to scientific inquiry experiences (Hanauer and Dolan, 2014), we propose that more research is needed to understand how instructors can most effectively stimulate project ownership among undergraduates in CUREs. Further, including more rounds of peer review (Richer, 1992; Lu and Bol, 2007) and fewer assessments throughout the course may allow GTAs in the CURE more time to provide meaningful, formative feedback on students' research proposals and scientific papers.

On the basis of GTA responses and feedback from a pilot study we conducted with three different GTAs teaching this same CURE in Fall 2016, we did not feel that any additional interview questions had to be included in the current study, nor did we feel that our study was missing important aspects of the GTA experience by omitting certain questions. However, we recognize that our study focused on 11 GTAs at one 4-year public university who were all instructing one specific CURE for introductory biology students. While we hope our findings encourage discussion about how to implement effective training for GTAs instructing CUREs, we acknowledge that the interview responses from GTAs in our study may not reflect the perceptions of GTAs instructing biology CUREs at other institutions. Thus, future studies will certainly need to focus on different aspects of the GTA experience in CUREs, or even explore a single challenge or benefit that we found in our current work in more detail, and should include a broader range of GTAs (e.g., with varying levels of teaching experience) instructing biology CUREs at different types of postsecondary institutions (community colleges, top-tier research universities, etc.).

If both CUREs (Bangera and Brownell, 2014) and GTAs (Benjamin, 2002; Jaeger, 2008) have the ability to increase retention among undergraduate students in STEM laboratories, a more complete understanding of GTA teaching challenges and rewards in CUREs, including more affective aspects of teaching, is necessary before a more widespread implementation of CUREs across institutions takes place. Greater focus on how best to improve the CURE and the experience for the GTA instructor may subsequently improve retention among undergraduates. 


\section{ACKNOWLEDGMENTS}

We thank Randy Larkins for his assistance with and support of this research project and Angela Geraghty for collaboration in devising and conducting a pilot study upon which this work was based. We also thank the GTA and student participants, as well as everyone who provided feedback on the many drafts of this article, including the two anonymous reviewers. This study was not funded by any grants.

\section{REFERENCES}

Aronson, J. (1994). A pragmatic view of thematic analysis. Qualitative Report, 2(1), 1-3.

Atkinson, R. L., Atkinson, R. C., Smith, E. E., \& Hilgard, H. R. (1987). Introduction to psychology (9th ed.). San Diego, CA: Harcourt Brace Jovanovich.

Auchincloss, L. C., Laursen, S. L., Branchaw, J. L., Eagan, K., Graham, M. Hanauer, D. I., ... \& Towns, M. (2014). Assessment of course-based undergraduate research experiences: A meeting report. CBE-Life Sciences Education, 13(1), 29-40.

Baldwin, R. G., \& Wawrzynski, M. R. (2011). Contingent faculty as teachers: What we know; What we need to know. American Behavioral Scientist, 55(11), 1485-1509.

Bangera, G., \& Brownell, S. E. (2014). Course-based undergraduate research experiences can make scientific research more inclusive. CBE-Life Sciences Education, 13(4), 602-606.

Baroody, A. J. (2003). The development of adaptive expertise and flexibility: The integration of conceptual and procedural knowledge. In Baroody, A. (Ed.), The Development of arithmetic concepts and skills: Constructing adaptive expertise (pp. 1-33). Abingdon, UK: Routledge.

Barrus, J. L. (1974). Preparing teaching assistants. Journal of College Science Teaching, 3(5), 350-352.

Beijaard, D., Verloop, N., \& Vermunt, J. D. (2000). Teachers' perceptions of professional identity: An exploratory study from a personal knowledge perspective. Teaching and Teacher Education, 16(7), 749-764.

Benjamin, E. (2002). How over reliance upon contingent appointments diminishes faculty involvement in student learning. Peer Review, 5(1), 4-10.

Benvenuto, M. (2002). Educational reform: Why the academy doesn't change. Thought \& Action, 18(1/2), 63-74.

Berliner, D. C. (1988). Implications of studies on expertise in pedagogy for teacher education and evaluation. New directions for teacher assessment (Proceeding of the 1988 ETS Invitational Conference, pp. 39-68). Princeton, NJ: Educational Testing Service.

BioTAP. (2019). Biology Teaching Assistant Project. Retrieved January 4, 2019, from https://biotap.utk.edu

Bogdan, R., \& Taylor, S. J. (1989). Relationships with severely disabled people: The social construction of humanness. Social Problems, 36(2), 135-148

Bond-Robinson, J., \& Rodriques, R. A. B. (2006). Catalyzing graduate teaching assistants' laboratory teaching through design research. Journal of Chemical Education, 83(2), 313

Brownell, S. E., \& Kloser, M. J. (2015). Towards a conceptual framework for measuring the effectiveness of course-based undergraduate research experiences in undergraduate biology. Studies in Higher Education, 40(3), 525-544

Brownell, S. E., Kloser, M. J., Fukami, T., \& Shavelson, R. (2012). Undergraduate biology lab courses: Comparing the impact of traditionally based "cookbook" and authentic research-based courses on student lab experiences. Journal of College Science Teaching, 41(4), 36-45.

Brownell, S. E., \& Tanner, K. D. (2012). Barriers to faculty pedagogical change: Lack of training, time, incentives, and... tensions with professional identity? CBE-Life Sciences Education, 11(4), 339-346.

Buck, L. B., Bretz, S. L., \& Towns, M. H. (2008). Characterizing the level of inquiry in the undergraduate laboratory. Journal of College Science Teaching, 38, 52-88.

Carnevale, A. P. (1990). Workplace basics: The essential skills employers want (ASTD best practices series: Training for a changing work force) (94104). San Francisco, CA: Jossey-Bass

Casner-Lotto, J., \& Barrington, L. (2006). Are they really ready to work? Employers' perspectives on the basic knowledge and applied skills of new entrants to the 21st century US workforce. Washington, DC: Partnership for 21st Century Skills.

Clark, D. J., \& McLean, K. (1979). Teacher training for teaching assistants. American Biology Teacher, 41(3), 140-144.

Clary, R. M., \& Wandersee, J. H. (2015). Using controversy and argumentation to develop students' critical thinking skills. In Innovations in college science teaching 2015 (pp. 115-130). Arlington, VA: Society for College Science Teachers.

Conley, D. T., \& French, E. M. (2014). Student ownership of learning as a key component of college readiness. American Behavioral Scientist, 58(8), 1018-1034.

Corwin, L. A., Graham, M. J., \& Dolan, E. L. (2015). Modeling course-based undergraduate research experiences: An agenda for future research and evaluation. CBE-Life Sciences Education, 14(1), es1.

Corwin, L. A., Runyon, C. R., Ghanem, E., Sandy, M., Clark, G., Palmer, G. C., ... \& Dolan, E. L. (2018). Effects of discovery, iteration, and collaboration in laboratory courses on undergraduates' research career intentions fully mediated by student ownership. CBE-Life Sciences Education, 17(2), ar20.

Costin, F., Greenough, W. T., \& Menges, R. J. (1971). Student ratings of college teaching: Reliability, validity, and usefulness. Review of Educational Research, 41(5), 511-535.

Crawford, B. A. (2007). Learning to teach science as inquiry in the rough and tumble of practice. Journal of Research in Science Teaching, 44(4), 613642

Creswell, J. W. (2013). Qualitative inquiry and research design: Choosing among five approaches. Thousand Oaks, CA: Sage.

Crotty, M. (1998). The foundations of social research: Meaning and perspective in the research process. Thousand Oaks, CA: Sage.

Dolan, E. L. (2016). Course-based undergraduate research experiences: Current knowledge and future directions (National Research Council commissioned paper). Washington, DC: National Research Council.

Domin, D. (1999). A review of laboratory instruction styles. Journal of Chemical Education, 76, 543-547.

Druger, M. (1997). Preparing the next generation of college science teachers. Journal of College Science Teaching, 26(6), 424.

Ethington, C. A., \& Pisani, A. (1993). The RA and TA experience: Impediments and benefits to graduate study. Research in Higher Education, 34(3), 343-354.

French, D., \& Russell, C. (2002). Do graduate teaching assistants benefit from teaching inquiry based laboratories? BioScience, 52, 1036-1104.

Gardner, S. K., \& Barnes, B. J. (2007). Graduate student involvement: Socialization for the professional role. Journal of College Student Development, 48(4), 369-387.

Goodwin, E. C., Cao, J. N., Fletcher, M., Flaiban, J. L., \& Shortlidge, E. E. (2018). Catching the wave: Are biology graduate students on board with evidence-based teaching? CBE-Life Sciences Education, 17(3), ar43.

Gormally, C., Brickman, P., Hallar, B., \& Armstrong, N. (2009). Effects of inquiry-based learning on students' science literacy skills and confidence. International Journal for the Scholarship of Teaching and Learning, 3(2), 16

Gottesman, A. J., \& Hoskins, S. G. (2013). CREATE Cornerstone: Introduction to scientific thinking, a new course for STEM-interested freshmen, demystifies scientific thinking through analysis of scientific literature. CBE-Life Sciences Education, 12(1), 59-72.

Halpern, D. F., \& Hakel, M. D. (2002). Learning that lasts a lifetime: Teaching for long-term retention and transfer. New Directions for Teaching and Learning, 2002(89), 3-7.

Hanauer, D. I., \& Dolan, E. L. (2014). The project ownership survey: Measuring differences in scientific inquiry experiences. CBE-Life Sciences Education, 13(1), 149-158.

Hanauer, D. I., Frederick, J., Fotinakes, B., \& Strobel, S. A. (2012). Linguistic analysis of project ownership for undergraduate research experiences. CBE-Life Sciences Education, 11(4), 378-385.

Hanauer, D. I., Nicholes, J., Liao, F. Y., Beasley, A., \& Henter, H. (2018). Shortterm research experience (SRE) in the traditional lab: Qualitative and quantitative data on outcomes. CBE-Life Sciences Education, 17(4), ar64. 
Handelsman, J., Ebert-May, D., Beichner, R., Bruns, P., Chang, A., Dehaan, R., .. \& Wood, W. B. (2004). Scientific teaching. Science, 304(5670), 521522

Harrison, M., Dunbar, D., Ratmansky, L., Boyd, K., \& Lopatto, D. (2011). Classroom-based science research at the introductory level: Changes in career choices and attitude. CBE-Life Sciences Education, 10(3), 279-286

Hassel, H., \& Lourey, J. (2005). The dea(r)th of student responsibility. College Teaching, 53(1), 2-13.

Holt, C. E., Abramoff, P., Wilcox, L. V., \& Abell, D. L. (1969). Investigative laboratory programs in biology: A position paper of the Commission on Undergraduate Education in the Biological Sciences. BioScience, 19(12), 1104-1107.

Howard, D. R., \& Miskowski, J. A. (2005). Using a module-based laboratory to incorporate inquiry into a large cell biology course. Cell Biology Education, 4(3), 249-260

Howell, C. L. (2002). Reforming higher education curriculum to emphasize student responsibility: Waves of rhetoric but glacial change. College Teaching, 50(3), 116-120.

Hughes, P. W., \& Ellefson, M. R. (2013). Inquiry-based training improves teaching effectiveness of biology teaching assistants. PLOS ONE, 8(10), e78540.

Hunter, A. B., Laursen, S. L., \& Seymour, E. (2007). Becoming a scientist: The role of undergraduate research in students' cognitive, personal, and professional development. Science Education, 91(1), 36-74

Hutchins, K. L., \& Friedrichsen, P. J. (2012). Science faculty belief systems in a professional development program: Inquiry in college laboratories. Journal of Science Teacher Education, 23(8), 867-887.

Isaak, D. J., \& Hubert, W. A. (1999). Catalyzing the transition from student to scientist-a model for graduate research training. BioScience, 49(4), $321-326$.

Jaeger, A. J. (2008). Contingent faculty and student outcomes. Academe, 94(6), 42 .

Jones, J. L. (1993). TA training: From the TA's point of view. Innovative Higher Education, 18(2), 147-161.

Jordan, T. C., Burnett, S. H., Carson, S., Caruso, S. M., Clase, K., DeJong, R. J., ... \& Findley, A. M. (2014). A broadly implementable research course in phage discovery and genomics for first-year undergraduate students. MBio, 5(1), e01051-13.

Kloser, M. J., Brownell, S. E., Chiariello, N. R., \& Fukami, T. (2011). Integrating teaching and research in undergraduate biology laboratory education. PLoS Biology, 9(11), e1001174.

Knowles, J. G. (2013). Models for understanding pre-service and beginning teachers' biographies: Illustrations from case studies. In Goodison, I. (Ed.), Studying teachers' lives (pp. 111-164). London, UK: Routledge.

Knowles, M. S. (1975). Self-directed learning. New York: Association Press

Kram, K. E. (1988). Mentoring at work: Developmental relationships in organizational life. Lanham, MD: University Press of America.

Kurdziel, J. P., \& Libarkin, J. C. (2003). Research methodologies in science education: Training graduate teaching assistants to teach. Journal of Geoscience Education, 51(3), 347

Lester, S. (1999). An introduction to phenomenological research. Retrieved September 9, 2018, from www.researchgate.net/profile/Stan_Lester/ publication/255647619_An_introduction_to_phenomenological _research/links/545a05e30cf2cf5164840df6.pdf

Lopatto, D., Alvarez, C., Barnard, D., Chandrasekaran, C., Chung, H. M., Du, C., ... \& Kopp, O. R. (2008). Genomics Education Partnership. Science, 322(5902), 684-685.

Lu, R., \& Bol, L. (2007). A comparison of anonymous versus identifiable e-peer review on college student writing performance and the extent of critical feedback. Journal of Interactive Online Learning, 6(2), 100-115.

Luft, J. A., Kurdziel, J. P., Roehrig, G. H., \& Turner, J. (2004). Growing a garden without water: Graduate teaching assistants in introductory science laboratories at a doctoral/research university. Journal of Research in Science Teaching, 41(3), 211-233

McComas, W. F., \& Cox, A. M. (1999). Enhancing undergraduate science instruction-the G-step approach. Journal of College Science Teaching. 29(2), 120

McPherson, G. R. (2001). Teaching \& learning the scientific method. American Biology Teacher, 63(4), 242-245.
Merriam, S. B., \& Tisdell, E. J. (2016). Qualitative research: A guide to design and implementation. San Francisco, CA: Wiley.

Modell, H. I., \& Michael, J. A. (1993). Promoting active learning in the life science classroom: Defining the issues. Annals of the New York Academy of Sciences, 701(1), 1-7.

Muzaka, V. (2009). The niche of graduate teaching assistants (GTAs): Perceptions and reflections. Teaching in Higher Education, 14(1), 1-12.

National Academies of Sciences, Engineering, and Medicine. (2017) Undergraduate research experiences for STEM students: Successes, challenges, and opportunities. Washington, DC: National Academies Press.

National Academies of Sciences, Engineering, and Medicine. (2019). Committee on Revitalizing Graduate STEM Education for the 21st Century: Discussion document. Retrieved January 4, 2019, from http:// sites.nationalacademies.org/pga/bhew/graded/pga_180817\#_edn2

National Institutes of Health: Department of Health and Human Services (2019). National Institute of General Medical Sciences Ruth L. Kirschstein National Research Service Award (NRSA) Predoctoral Institutional Research Training Grant. Retrieved January 4, 2019, from https://grants.nih gov/grants/guide/pa-files/par-17-341.html

National Science Foundation. (2016). Doctorate recipients from U.S. universities: 2015 (Special report NSF 17-306). Arlington, VA. Retrieved January 4, 2019, from www.nsf.gov/statistics/2017/nsf17306/, Table 46.

Nyquist, J. D., \& Wulff, D. H. (1996). Working effectively with graduate assistants. Thousand Oaks, CA: Sage.

Olimpo, J. T., Fisher, G. R., \& DeChenne-Peters, S. E. (2016). Development and evaluation of the Tigriopus course-based undergraduate research experience: Impacts on students' content knowledge, attitudes, and motivation in a majors introductory biology course. CBE-Life Sciences Education, 15(4), ar72.

Park, C. (2004). The graduate teaching assistant (GTA): Lessons from North American experience. Teaching in Higher Education, 9(3), 349-361.

Parsons, S., Williams, B., Burrowbridge, S., \& Mauk, G. (2011). The case for adaptability as an aspect of reading teacher effectiveness. Voices from the Middle, 19(1), 19

QSR International. (2018). NVivo 12. Doncaster, VIC, Australia.

Reason, R. D., Terenzini, P. T., \& Domingo, R. J. (2006). First things first: Developing academic competence in the first year of college. Research in Higher Education, 47(2), 149-175.

Richer, D. L. (1992). The effects of two feedback systems on first year college students writing proficiency. Dissertation Abstracts International, 53(08A), 2722

Rodenbusch, S. E., Hernandez, P. R., Simmons, S. L., \& Dolan, E. L. (2016). Early engagement in course-based research increases graduation rates and completion of science, engineering, and mathematics degrees. CBE-Life Sciences Education, 15(2), ar20

Rowland, S. L., Lawrie, G. A., Behrendorff, J. B., \& Gillam, E. M. (2012). Is the undergraduate research experience (URE) always best?: The power of choice in a bifurcated practical stream for a large introductory biochemistry class. Biochemistry and Molecular Biology Education, 40(1) 46-62.

Ryker, K., \& McConnell, D. (2014). Can graduate teaching assistants teach inquiry-based geology labs effectively? Journal of College Science Teaching, 44(1), 56-63.

Shaffer, C. D., Alvarez, C., Bailey, C., Barnard, D., Bhalla, S., Chandrasekaran, C., ... \& Eckdahl, T. T. (2010). The Genomics Education Partnership Successful integration of research into laboratory classes at a diverse group of undergraduate institutions. CBE-Life Sciences Education, 9(1), 55-69.

Shaffer, C. D., Alvarez, C. J., Bednarski, A. E., Dunbar, D., Goodman, A. L. Reinke, C., ... \& Bazinet, C. (2014). A course-based research experience: How benefits change with increased investment in instructional time. CBE-Life Sciences Education, 13(1), 111-130.

Shannon, D. M., Twale, D. J., \& Moore, M. S. (1998). TA teaching effectiveness: The impact of training and teaching experience. Journal of Higher Education, 69(4), 440-466.

Shortlidge, E. E., Bangera, G., \& Brownell, S. E. (2016). Faculty perspectives on developing and teaching course-based undergraduate research experiences. BioScience, 66(1), 54-62. 
Shortlidge, E. E., Bangera, G., \& Brownell, S. E. (2017). Each to their own CURE: Faculty who teach course-based undergraduate research experiences report why you too should teach a CURE. Journal of Microbiology \& Biology Education, 18(2), 18.2.29.

Shortlidge, E. E., \& Eddy, S. L. (2018). The trade-off between graduate student research and teaching: A myth? PLOS ONE, 13(6), e0199576.

Sorcinelli, M. D. (1994). Effective approaches to new faculty development. Journal of Counseling \& Development, 72(5), 474-479.

Stefanou, C. R., Perencevich, K. C., DiCintio, M., \& Turner, J. C. (2004). Supporting autonomy in the classroom: Ways teachers encourage student decision making and ownership. Educational Psychologist, 39(2), 97110.

Sternberg, R. J., \& Horvath, J. A. (1995). A prototype view of expert teaching. Educational Researcher, 24(6), 9-17.

Tanner, K. D. (2013). Structure matters: Twenty-one teaching strategies to promote student engagement and cultivate classroom equity. CBE-Life Sciences Education, 12(3), 322-331.

Taylor, S. J., Bogdan, R., \& DeVault, M. (2015). Introduction to qualitative research methods: A guidebook and resource. Hoboken, NJ: Wiley.
Thomas, D. R. (2006). A general inductive approach for analyzing qualitative evaluation data. American Journal of Evaluation, 27(2), 237-246.

Tinto, V. (1993). Leaving college: Rethinking the causes and cures of student attrition (2nd ed.). Chicago: University of Chicago Press.

Vaughn, W. (1998). Apprentice or employee? Graduate students and their unions. Academe, 84(6), 43-49.

Volkmann, M. J., \& Zgagacz, M. (2004). Learning to teach physics through inquiry: The lived experience of a graduate teaching assistant. Journal of Research in Science Teaching, 41(6), 584-602.

Weaver, G. C., Russell, C. B., \& Wink, D. J. (2008). Inquiry-based and research-based laboratory pedagogies in undergraduate science. Nature Chemical Biology, 4(10), 577.

Wei, C. A., \& Woodin, T. (2011). Undergraduate research experiences in biology: Alternatives to the apprenticeship model. CBE-Life Sciences Education, 10(2), 123-131.

Williams, T. L., \& Baumann, J. F. (2008). Contemporary research on effective elementary literacy teachers. In 57th yearbook of the National Reading Conference (pp. 357-372). Oak Creek, WI: National Reading Conference. 